\title{
Hydrodynamics of the Rhine ROFI near IJmuiden
}

\author{
J.J. Nauw ${ }^{1}$ and M. van der Vegt ${ }^{2}$ \\ ${ }^{1}$ Royal Netherlands Institute for Sea Research, P.O. Box 59, 1790 AB Den Burg (Texel), the Netherlands, e-mail: \\ Janine.Nauw@nioz.nl \\ ${ }^{2}$ Institute for Marine and Atmospheric Research Utrecht - Physical Geography, Utrecht University, P.O. Box 80.115, 3508 TC \\ Utrecht, The Netherlands
}

\begin{abstract}
The paper will focus on hydrodynamics of the Rhine ROFI in its most northerly extent near IJmuiden. A bottom-mounted ADCP was deployed near IJmuiden and measured for almost 6 months. Observations show that the largest difference in ellipticity between surface and bottom mostly occurred during neap tide, suggesting that the water column was stratified, leading to a cross-shore circulation. However, for 3 out of the 11 neap tides no ellipticity difference was observed and during 1 out of the 10 spring tides a strong ellipticity difference occurred. To understand the causes of these irregularities a model was set up with GOTM. Based on the depth-averaged currents the barotropic pressure gradient is determined. Using a simple advection equation the salinity profile was estimated at the measurement location and used as input for the model. We were able to simulate the overall characteristics of the observed flow patterns. Model results show a strong link between wind stress magnitude and direction and reduced stratification during low energetic neap tides. An increased fresh water discharge was the cause for the strong ellipticity difference during spring tide. The strong effect of wind speed and direction on the onset of stratification of the Rhine ROFI has never been shown before. Furthermore, the results show that during the 150 days of observations the plume always reached IJmuiden.
\end{abstract}

\section{INTRODUCTION}

The focus of this paper is on the effect of the Rhine outflow, tidal conditions and meteorological forcing on the velocity profiles near the port of IJmuiden. A better understanding of the effects of human interventions (for example the construction of Maasvlakte 2 ) on the transport of freshwater and fines near the Dutch coast is needed and measurements play a crucial role therein. The river Rhine debouches into the North Sea near the port of Rotterdam. It creates a buoyant freshwater plume that drives a coastal current to the north due to the Coriolis force. The resulting cross-shore and alongshore density differences have a clear imprint on the tidal and on the tidally averaged currents. Averaged over tides the freshwater plume drives a mean circulation to the north and a circulation in the cross-shore where currents near the bottom are directed landward and seaward near the surface. This circulation transports suspended matter to the coast and is one of the reasons of the increased mud transport in the nearshore region. The interaction between tides, vertical mixing and stratification may result in periodic stratification. While on the one hand tides cause mixing of the water column, on the other hand the shear in the tidal currents results in transport of fresher water over saline waters, reducing mixing and enhancing stratification. These competing mechanisms can be captured by the Simpson number (horizontal Richardson number) as defined in Stacey et al. [2001] based on the earlier work on strain induced periodic stratification (SIPS) of the Rhine ROFI by Simpson [1990]:

$$
R i_{x}=\frac{\beta g S_{x} H^{2}}{u_{*}^{2}}
$$

where $S_{x}$ is the horizontal salinity gradient, $\beta=7.710^{-4} \mathrm{PSU}^{-1}$ is the influence of salinity on the density, $g$ is gravitational acceleration, $H$ is water depth and $u *$ is the friction velocity. When the Simpson number is larger than a critical value (typically taken as 0.1 ) the water column can be stratified near neap tides but well-mixed near spring tides, for smaller than critical values the water column is well-mixed during the entire spring-neap cycle, for much larger than critical values the water column is stratified during the whole spring-neap tidal cycle. When the water column is stratified this strongly impacts on the observed tidal currents. Stratification results in reduced mixing, causing the upper and lower water column to decouple, which results in opposite rotating current vectors in the top and bottom layers [Souza and Simpson, 1996]. These counter rotating currents result in periodic up- and downwelling near the coast [de Boer et al., 2009], affecting stratification but also the transport of fines.

The vertical structure of the freshwater plume is also affected by winds. Munchow and Garvine [1993] and Visser [1994] argue that upwelling winds enhance stratification, while downwelling winds reduce it. Joordens et al. [2001] have shown how a period of strong downwelling winds may have limited the freshwater transport and hence intensified density gradients. When the wind relaxed the enhanced density gradients drove a stronger flow, enhancing mean and semi-diurnal stratification. Wind driven currents may also enhance mixing thereby reducing the vertical salinity gradients.

The aim of this paper is to study the effect of tides, winds and waves on the hydrodynamics near IJmuiden. We have a unique half year dataset of observed 1D velocity profiles and for two periods of 26 and 10 days, respectively, also concurrent salinity and temperature observations. Using these data and the model results obtained with the GOTM model we will show the dynamic nature of the plume near IJmuiden and discuss the effects of wind and tides on the onset of stratification and the imprint on the observed velocity profiles. 


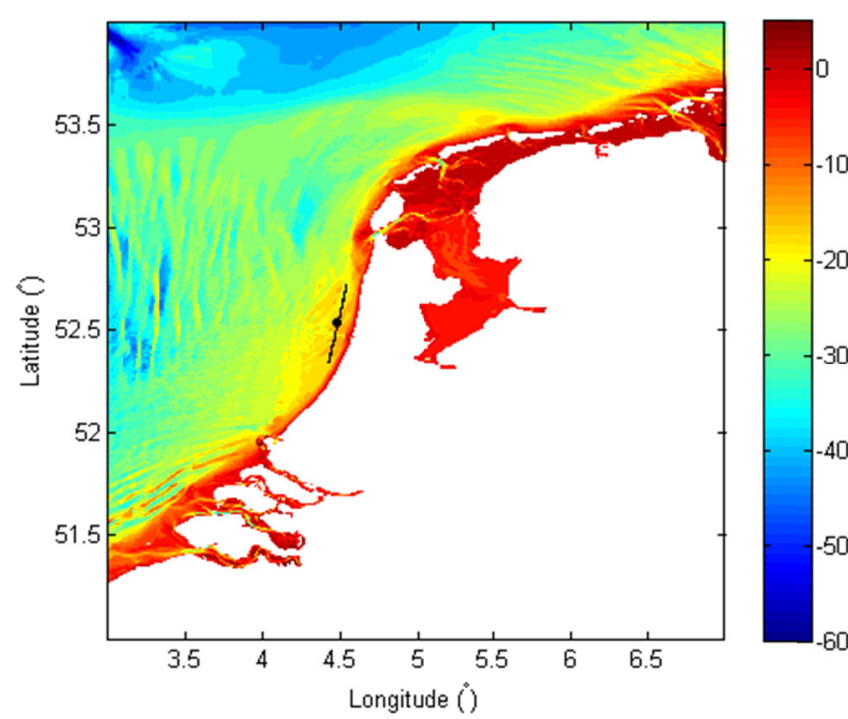

Figure 1. Bathymetry in the Dutch part of the Southern North Sea. The black dot indicates the location of the mooring and the drawn line shows the tidal 'ellipse'.

\section{MEASUREMENTS}

A broadband $1200 \mathrm{kHz}$ Acoustic Doppler Current profiler (ADCP) was moored on the bottom at $52^{\circ} 32^{\prime} \mathrm{N}$ and $4^{\circ} 29^{\prime} \mathrm{E}$. This is about $7 \mathrm{~km}$ offshore from IJmuiden (the Netherlands) and 65 $\mathrm{km}$ North East of the Rotterdam harbor. There the bulk of the river Rhine outflow enters the North Sea. The mooring was deployed on August 24, 2007 and recovered on January 22, 2008 leading to a time-series of 150 days. The ADCP has four transducers at an angle of $30^{\circ}$. It uses the Doppler shift to measure the velocity in these four directions. An internal compass is used to transform the velocities into earth coordinates and additionally an estimate of the error is given. The cell size and the blanking distance were 0.5 $\mathrm{m}$. The lowest bin was located at $1.78 \mathrm{~m}$ above the bottom. We used 30 pings per ensemble and 25 seconds per ping. The ensembles were stored every 15 minutes.

Within $100 \mathrm{~m}$ of the location of the ADCP a lander was placed containing a Sea-Bird SBE37. It recorded every 5 minutes the salinity, temperature and pressure at $1.5 \mathrm{~m}$ above the bed from August 23 to September 17, 2007 and from 1 to 10 October, 2007.

Unfortunately, the ADCP was not equipped with a pressure sensor, so the exact depth of the water column was not recorded. For the days the lander and ADCP measured concurrently the water surface was determined by the lander. For the other days the water surface was estimated by determining the cell number at which the backscatter intensity gradient is maximal for each different beam separately. This cell number was corrected for pitch and roll. This leads to four estimates of the cell number in which the surface is located. After despiking the depth estimates with a median filter over a window length of 7 and a detection limit of 1 , the average is taken over each of the four beams. However, if the standard deviation between the four estimates is larger than 0.5 the data is discarded. The depth levels and velocities have been corrected for the true speed of sound, which was set at its default value of $1500 \mathrm{~m} / \mathrm{s}$. The velocity data was transformed onto sigma coordinates. A total of 25 levels was adopted in the vertical equally distributed over the total
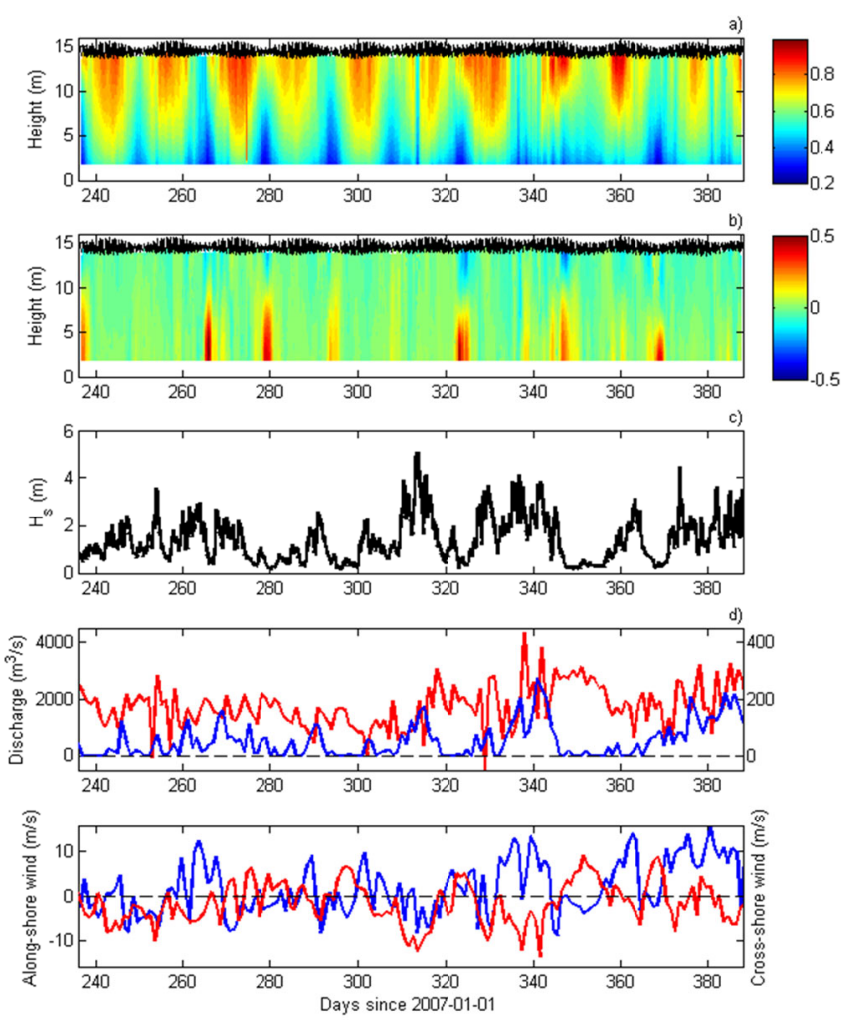

Figure 2. a) Semi-major axis $(\mathrm{m} / \mathrm{s})$ and b) ellipticity of the M2 tidal ellipse for each depth cell; c) Significant wave height at IJmuiden; d) fresh water discharge (thin line and left axis: Rhine at Hoek van Holland; thick line and right axis: North Sea Channel at IJmuiden) from www.waterbasie.nl e) Wind speed in the alongshore (left, blue) and cross-shore direction (right, red) from www.knmi.nl.

measurement depth, e.g. from the lowest to the highest bin. This leads to an average bin size of about $0.5 \mathrm{~m}$, which is similar to the original bin size.

\section{OBSERVATIONS}

First, a least squares harmonic analysis (LSHA) with a window length of 15 days was applied to the depth averaged eastward and northward velocity. For this the T-TIDE package [Pawlowicz, 2002] was used. The 35 most important tidal constituents and shallow water constituents were used in the analysis. A total of 84 (94) $\%$ of the total variance is explained in the eastward (northward) direction. The residual depth average velocity is only $\left(u_{0}, v_{0}\right)=(0.4,2.9) \mathrm{cm} / \mathrm{s}$. From the results of the LSHA, the M2 tidal ellipse parameters were determined. The semi-major axis was relatively small: $0.56 \mathrm{~m} / \mathrm{s}$. The ellipticity is $\varepsilon=-6 \cdot 10^{-3}$, indicating that the depth averaged flow was almost rectilinear on the dominant M2 tidal frequency. The inclination was $72.8^{\circ}$, which is comparable to the local orientation of the coast and the bathymetry (Figure 1). The velocities in all sigma layers were rotated over this angle to determine the along- and cross-shore velocity, $(u, v)$.

Next, the depth-varying cross-shore and alongshore currents were analyzed using a running mean LSHA with a window length of 25 hours. Only the M2 tidal constituent was retrieved and 
attributed to each sigma level. Also the tidal ellipse parameters were derived. The semi-major axis and the ellipticity for the 150 day time-series are shown in Figure 2a,b. The semi-major axis showed the dominant spring-neap tidal cycle and a decrease in speed over depth. Not all variability of the major axis can be attributed to the spring-neap cycle.

The ellipticity (Figure 2b) showed several events with a large difference between the surface and near bottom value. Such a difference is usually an indication of the presence of stratification [Souza and Simpson, 1996]. In these cases the ellipses near the surface (bottom) rotate (counter)clockwise. The largest top-bottom ellipticity differences occurred around days 236, 265, 279, 323, 346 and 369 when the maximum difference in ellipticity between the bottom and the surface exceeded 0.4 .

Most events with large ellipticity differences occurred during neap tide, except for the one on day 346 (2007-12-12), which is exactly at maximum spring. The conditions during this event were characterized by weak winds directed offshore and significant wave heights less than $1 \mathrm{~m}$. Moreover, this event was preceded by a peak in fresh water discharged from the North Sea Channel (IJmuiden), likely enhancing the horizontal stratification locally/temporally.

Focusing on the neap tides; only a weak ellipticity difference was found on days 293, 338 and 384 and no significant events occurred on days 249,307 and 352 . The significant wave height and wind speed were small on day 249 and 307, but winds were directed onshore, favoring downwelling and thereby relaxing stratification, if present. Although waves were small and wind direction was offshore on day 352 , wind speeds exceeded $10 \mathrm{~m} / \mathrm{s}$ the day before, which probably induced strong mixing.

\section{MODELING WITH GOTM}

In the hydrographic measurements we have observed events of strong ellipticity difference between the surface and the bottom during one spring tide and most but not all neap tides. Although, previous studies suggest this is caused by a stratified water column, we do not have direct measurements to proof this. However, we have observations of the salinity and temperature near the bottom during almost 35 days. Using the available data and a model we try to simulate the hydrodynamics and salinity dynamics in the vertical. For this purpose we used the General Ocean Turbulence Model (GOTM, see Umlauf and Burchard, [2005] for a review) to model the hydrodynamic behavior of the currents near IJmuiden under certain conditions. GOTM is a onedimensional water column model for marine applications. It is coupled to a choice of traditional as well as state-of-the-art parameterizations for vertical turbulent mixing. In the model runs below, we use a standard second order turbulent closure model.

\section{Setup and forcing conditions}

The model was set up for a column at the location of the mooring in the North Sea where the total depth was $14.5 \mathrm{~m}$. The column was divided into 35 levels and the time step was set to 100 s. The model was forced with an external pressure gradient which was inferred from the depth averaged velocities measured with the ADCP. A linear equation of state was used:

$$
\rho=\rho_{0}+\alpha\left(T-T_{0}\right)+\beta\left(S-S_{0}\right)
$$

in which $\rho_{0}=1022 \mathrm{~kg} / \mathrm{m}^{3}$ is a reference density and $T_{0}=17.4{ }^{\circ} \mathrm{C}$ and $S_{0}=31.8$ are the reference temperature and salinity. These are the averaged values from the measurements of the nearby CTD. The thermal and haline expansion coefficients are $\alpha=-0.2316 \mathrm{kgm}^{-3} \mathrm{~K}^{-1}$ and $\beta=0.7741 \mathrm{kgm}^{-3}$ and were derived by least-squares fitting equation (1) to the data. Note that this definition of $\beta$ differs from the one used for the horizontal Richardson number in equation (1) in the introduction. Meteorological forcing was obtained from KNMI (Royal Dutch Met Office) and the wind vector was rotated in an alongshore, $\tau_{x}$, and cross-shore, $\tau_{y}$, component.

The horizontal temperature and salinity gradients need to be prescribed in GOTM to generate estuarine type velocities. Since we did not have direct measurements of these values we derived them from least squares fitting a simple advection equation to the in-situ measurements of the velocity and (time-derivative) of the salinity or temperature:

$$
\frac{\partial \theta}{\partial t}=-u \frac{\partial \theta}{\partial x}-v \frac{\partial \theta}{\partial y}
$$

which was discretized in the following way:

$$
\frac{\theta^{n+1}-\theta^{n}}{\Delta t}=-0.5\left(u^{n+1}+u^{n}\right) \theta_{x}-0.5\left(v^{n+1}-v^{n}\right) \theta_{y}
$$

where $\theta$ is $T$ or $S$ and $x(y)$ is in the alongshore (cross-shore) direction and positive to the north northeast (offshore). Assuming that the horizontal gradients are relatively constant near the bottom for a period of two tidal cycles, a running least squares analysis was applied with a window length of 25 hours. The measurements of the CTD were close to the bottom, thus the alongshore and cross-shore velocities in the lowest sigma level were used. To suppress fast variations in the tracers, first a fivepoint running mean filter is applied to $\theta$, before calculating its time-derivative.

The salinity gradients in the alongshore and cross-shore direction (Figure 3a) show one prominent relatively broad peak around day $279 \mathrm{w}$

ith a cross-shore gradient of $\mathrm{S}_{y}=6 \cdot 10^{-4} \mathrm{~m}^{-1}$. The $\mathrm{R}^{2}$ was usually relatively low, except between days 278 and 280, where it was above 0.6. During this period the alongshore gradient, $S_{x}$, was negative, suggesting that the downstream salinity was lower. This
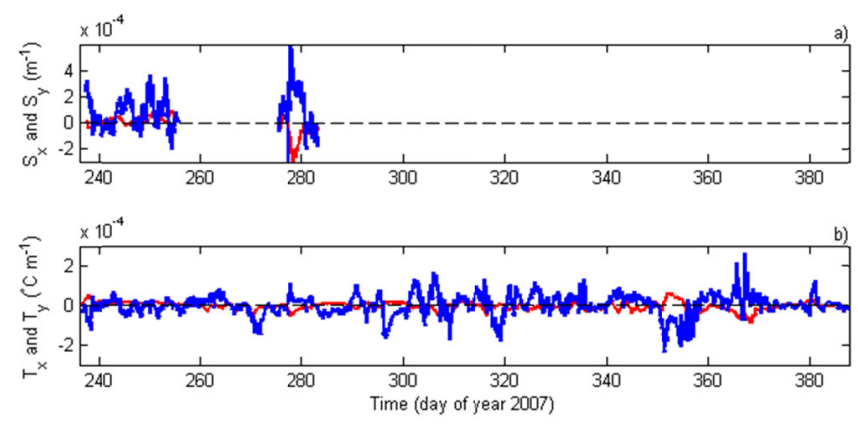

Figure 3. Horizontal gradient in the a) salinity and b) temperature in the alongshore (blue) and cross-shore (red) direction with positive values being to the north northeast in the $x$-direction and offshore in the $y$-direction. 
Table 1: Experimental setups.

\begin{tabular}{ccccc}
\hline $\begin{array}{c}\text { Experiment } \\
\#\end{array}$ & $\begin{array}{c}\text { Alongshore } \\
\text { salinity } \\
\text { gradient, } S_{x} \\
\left(\mathrm{~m}^{-1}\right)\end{array}$ & $\begin{array}{c}\text { Cross- } \\
\text { shore } \\
\text { salinity } \\
\text { gradient, } \\
S_{y}\left(\mathrm{~m}^{-1}\right)\end{array}$ & $\begin{array}{c}\text { Alongshore } \\
\text { wind } \\
\text { stress, } \tau_{x} \\
\left(\mathrm{Nm}^{-2}\right)\end{array}$ & $\begin{array}{c}\text { Cross- } \\
\text { shore } \\
\text { wind } \\
\text { stress, } \tau_{y} \\
\left(\mathrm{Nm}^{-2}\right)\end{array}$ \\
\hline 1a & 0 & $3.75 \cdot 10^{-4}$ & 0 & 0 \\
$1 \mathrm{~b}$ & 0 & $3.75 \cdot 10^{-4}$ & Realistic & Realistic \\
1c & $\begin{array}{c}\text { As Fig. 3a } \\
\text { As Fig. 3a }\end{array}$ & Realistic & Realistic \\
2a & $\begin{array}{c}-2.0 \cdot 10^{-4} \text { to } \\
6.0 \cdot 10^{-4}\end{array}$ & 0 & 0 & 0 \\
2b & 0 & $-2.0 \cdot 10^{-4}$ & 0 & 0 \\
3a & 0 & $3.75 \cdot 10^{-4}$ & -0.6 to 0.6 & 0 \\
3b & 0 & $3.75 \cdot 10^{-4}$ & 0 & -0.6 to 0.6 \\
\hline
\end{tabular}

could be caused by the pulse-like behavior of the river plume [ $d e$ Ruijter et al., 1997]. The ellipticity difference at day 237 also seems to be correlated with a peak in the cross-shore salinity gradient, $S_{y}$. Note that, of this peak only the second half was captured in the data.

At days 244, 245 and 250 no ellipticity difference was found (Figure 2b), although peaks of similar size were found in the cross-shore salinity gradient, $S_{y}$. Especially, the latter is interesting, because it occurred during neap tide. Temperature gradients do not appear to be related to salinity gradients (Figure $3 b)$.

\section{Basic Experiments}

We have set up a set of experiments to simulate the hydrodynamics and salinity dynamics as a function of the salinity gradient in the alongshore and cross-shore direction, the local wind stress (Table 1) and the barotropic pressure gradient that drive the tidal flow. In experiment 1a we forced the model with a constant cross-shore salinity gradient of $S_{y}=3.75 \cdot 10^{-4} \mathrm{~m}^{-1}$ (other gradients including those for the temperature are set to zero) and an external pressure gradient based on the depth-averaged velocities as in Burchard [1999]. A realistic sea level variation based on the measurements was also imposed, but wind and waves were neglected. In experiment $1 b$, added to this a realistic meteorological forcing was applied, derived from measurements by KNMI in IJmuiden, Wijk aan Zee, Schiphol and de Bilt. In experiment $1 \mathrm{c}$, instead of a constant cross-shore salinity gradient, the horizontal gradients as depicted Figure 3 were imposed (including the temperature gradients). Note that salinity gradients were assumed to be zero in the period for which we do not have measurements, e.g. from day 261 to 274 and from day 284 onwards.

We focus on the model results around day 280. This was a strong event for which we have the meteorological forcing as well as a good estimate of the horizontal temperature and salinity gradients. Figure 4 shows that both a realistic wind stress forcing and a realistic horizontal density gradient are essential to reproduce the phenomenon. If a constant horizontal cross-shore salinity gradient was imposed of $S_{y}=3.75 \cdot 10^{-4} \mathrm{~m}^{-1}$ an event with an
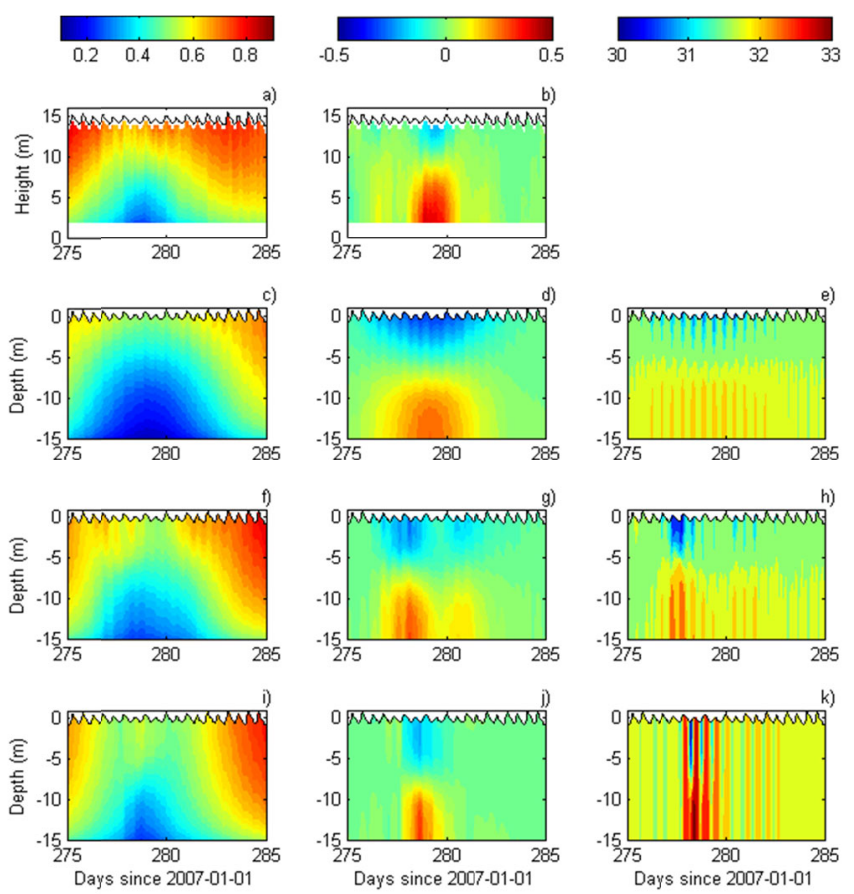

Figure 4. Left: Semi major axis $(\mathrm{m} / \mathrm{s})$, middle: ellipticity and right: salinity as a function of depth and time from the measurements (top panel) and the model simulations with constant $S_{y}=3.75 \cdot 10^{-4}$ $m^{-1}$ (second panel), with realistic wind stress forcing (third panel) and with horizontal gradients from Figure 3 (bottom panel).

ellipticity difference is reproduced, but the negative values of the ellipticity at the surface are too large compared to observations (exp. 1a and Figure 4c,d,e). The period with large ellipticity differences started earlier and continued longer compared with the measurements. Moreover, the semi-major axis showed that the velocities throughout the entire spring-neap tidal cycle and at every sigma level were underestimated by the model. The model output indeed showed a relation between the ellipticity difference

and a periodic (salinity) stratification with a maximum difference of $\Delta S_{\max }=1.6$ PSU. Imposing a realistic meteorological forcing (exp. 1b and Figure 4f,g,h), resultedl in improved correspondence between modeled and observed semi-major axis. The ellipticity difference became much more comparable to those in the measurements, however the timing of the event was still wrong. In fact, the event seemed to split up into two different events. The periodic stratification became stronger, $\Delta S_{\max }=2.2 \mathrm{PSU}$, and is still correlated with the ellipticity event(s). When the model was forced by the observed salinity and temperature gradients (exp. 1c and Figure $4 \mathrm{i}, \mathrm{j}, \mathrm{k}$ ), the timing and duration of the ellipticity event corresponded much better with the measured ones, although the modeled values of the ellipticity are a little too small, which suggests that the horizontal gradients are slightly different from the ones found in Figure 3. The periodic salinity stratification still only occurs during the ellipticity event and was slightly larger, $\Delta S_{\max }=2.4$ PSU. Now also a periodic pattern was observed before and after the event, but with sallinity values being constant throughout the entire water column. Overall, the model was quite sensitive to the forcing and best model-data agreement was obtained when the model had the moist realistic forcing. 

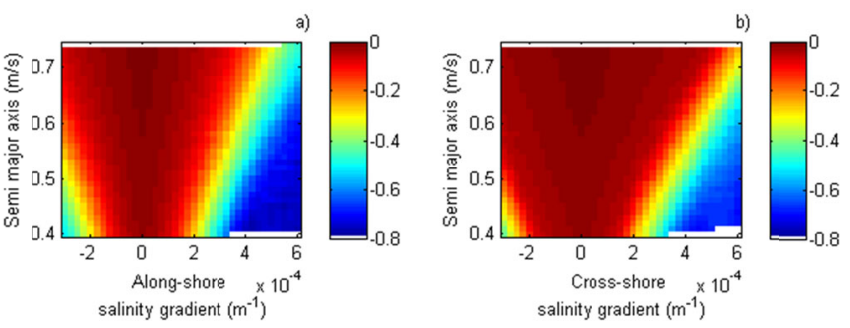

Figure 5. Ellipticity difference between the surface and bottom level for different values of the alongshore and cross-shore salinity gradient, $S_{x}$ and $S_{y}$, as a function of the depth-averaged semi-major axis.

\section{Horizontal salinity gradient}

In a second series of experiments the (fixed) alongshore salinity gradient was varied between $S_{x}=-2.0 \cdot 10^{-4}$ and $6.0 \cdot 10^{-4} \mathrm{~m}^{-1}$, while the cross-shore salinity gradient was kept zero (exp. $2 \mathrm{a}$ and the other way around in exp. $2 b$ ). The $\mathrm{M}_{2}$ tidal ellipse parameters were calculated for one spring neap tidal cycle. The ellipticity difference between the top and the bottom level was calculated and bin-averaged with respect to the depth-averaged value of the semi-major axis. The results are shown in Figure 5.

The ellipticity difference became increasingly more negative for higher salinity gradients as the ellipticity was negative at the surface and positive near the bottom. The ellipticity difference was close to zero when the salinity gradient was small. For quite a large portion of the phase space, the ellipticity difference was well below -0.1 but became more negative for larger negative values of the gradient. There was a sharp transition from conditions which result in a small difference in ellipticity between surface and bottom and conditions that resulted in large differences. For larger depth-averaged currents this transition occurred for stronger horizontal salinity gradients. The transition from small to large ellipticity differences (stratification) seemed to increase linearly as a function of tidal flow velocity. It occurred for values around $S_{x, y}=2.0 \cdot 10^{-4} \mathrm{~m}^{-1}$ at neap tide and at $S_{y}=6.0 \cdot 10^{-4} \mathrm{~m}^{-1}$ and $\mathrm{S}_{\mathrm{x}}=5.0 \cdot 10^{-}$ ${ }^{4} \mathrm{~m}^{-1}$ during spring tide. This figure clearly points out that the existence of an ellipticity difference is not solely connected to the neap tide, but may last throughout an entire spring-neap tidal cycle for horizontal cross-shore salinity gradients above $S_{y}=6.0 \cdot 10^{-4} \mathrm{~m}^{-1}$. This value corresponds with the maximum observed value during the measurement period (Figure 3a). Obviously, stratification events can be completely absent if the cross-shore salinity gradient remains below $S_{y}=1.0 \cdot 10^{-4} \mathrm{~m}^{-1}$.

Note that Figure $5 \mathrm{a}$ and $\mathrm{b}$ are not entirely symmetric around $S_{x, y}=0 \mathrm{~m}^{-1}$. This is because the system is not entirely symmetric. The barotropic forcing, which is based on the in-situ measurements gives rise to a small positive alongshore current. Besides that, the periodic stratification took place during the flood phase of the tide, if a positive cross-shore salinity gradient was applied and during the ebb phase, if the cross-shore salinity gradient was negative.

\section{Wind stress}

The effect of the wind stress on the ellipticity (as a proxy for stratification) was investigated in two series of experiments in which the alongshore (exp. 3a) and cross-shore (exp. 3b) wind stress was varied, respectively. In these experiments the crossshore horizontal salinity gradient was fixed to $S_{y}=3.75 \cdot 10^{-4}$, the
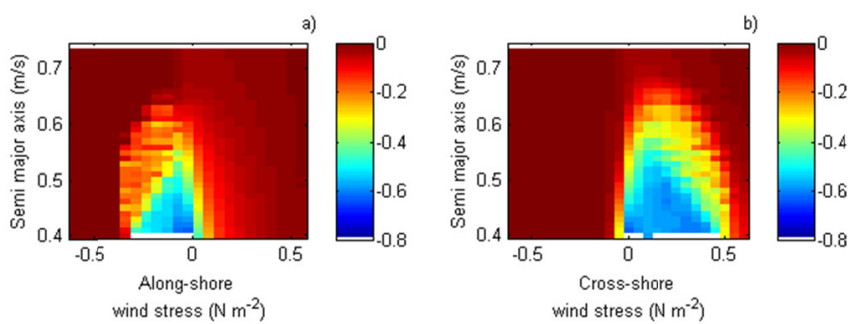

Figure 6. Same as Figure 5 but for the a) alongshore and b) cross-shore wind stress at a constant value of the horizontal salinity gradient $S_{y}=3.75 \cdot 10^{-4} \mathrm{~m}^{-1}$.

average value observed during our measurements. The wind-stress was varied from -0.6 to $+0.6 \mathrm{Nm}^{-2}$ in both directions separately. The maximum observed wind speed was $16 \mathrm{~m} / \mathrm{s}$, which corresponds to a wind stress of about $\tau=\rho_{a} C_{D} U^{2} \sim 0.5 \mathrm{Nm}^{-2}$ with the density of air $\rho_{a}=1.3 \mathrm{kgm}^{-3}$ and a drag coefficient $C_{D}=0.0015$. Figure 6 shows the ellipticity difference as a function of the alongshore and the cross-shore wind stress at a constant horizontal salinity gradient. The ellipticity difference was small for positive alongshore or downwelling (Figure 6a) and negative cross-shore or onshore winds (Figure 6b). The effect was largest by the crossshore winds. Onshore winds generated a small net onshore current, which caused saline water to be transported over fresher waters, resulting in enhanced vertical mixing and no stratification.. Negative alongshore winds (northerlies) and offshore winds generated an ellipticity difference. Both were characterized by an estuarine type of circulation around a large part of the neap phase (not shown). This exchange flow was enhanced by advection of fresher water over saline water, increasing stratification. Figures $6 \mathrm{a}$ and $\mathrm{b}$ are not mirror images, since the effect of a cross-shore current is much more direct than that of an alongshore currents. Thus, by inducing a cross-shore current, wind forcing can either increase or reduce the stratifying effect and thereby control the occurrence of an ellipticity (and stratification) event.

\section{DISCUSSION AND CONCLUSIONS}

In an analysis of the ellipse parameters in a unique 150-day long time-series of the horizontal velocity profiles, several events were observed during which a strong ellipticity difference occurred between the bottom and the surface. These events can be related to periodic stratification events, although no direct measurements are available of the stratification. The events seem to occur in regular intervals and to be correlated with the neap phases of the springneap tidal cycle. However, during 3 out of 11 neap phases of the tide no ellipticity difference was found, while during 3 others only a small signal could be observed. Moreover, such an ellipticity event was found even during one out of the 10 spring phases of the tide. Hence, the relation between the occurrence of an ellipticity (or stratification) event is more complicated than a simple correlation with the spring-neap tidal cycle.

The gross characteristics of the vertical salinity profile and tidal velocity profile could be simulated using the one-dimensional vertical column General Oceans Turbulence Model (GOTM). The model was forced with observed depth-averaged velocities, horizontal salinity gradients and wind.

A series of experiments showedl a quick transition from no ellipticity difference (hence, no stratification) to strong ellipticity 
differences (stratified water column) between the surface and bottom. This transition was a function of the horizontal salinity gradient, the magnitude of the depth-averaged currents and wind speed and direction. Stronger tidal currents resulted in less stratification, while increased spatial differences in salinities enhanced stratification. We further showed that wind has a very strong influence on the occurrence of stratification events. Landward directed and downwelling favoring alongshore winds diminished the effect of a significant cross-shore salinity gradient, while seaward directed and upwelling favoring winds enhanced stratification and the presence of ellipticity differences.. The effect of wind will probably even be stronger in 3D models when the presence of a nearby coast poses a boundary for onshore directed currents.

Using the model results, the absence or weakness of events during neap tides could all be explained by unfavorable wind directions or strong wind force. The stratification event that occurred during spring tide was preceded by a discharge event at the sluices of IJmuiden, thereby enhancing horizontal salinity gradients, and occurred during a period with weak offshore directed winds that enhanced the stratification.

Clearly, the existence of these events showed that the stratified region of the Rhine ROFI indeed reaches all the way to IJmuiden. Stratification could lead to an ellipticity event during neap tide, but since the horizontal salinity gradients were relatively small, any counteracting influence, such as the wind force or direction could already suppress such an event.

\section{REFERENCES}

de Boer, G. J., Pietrzak, J. D. and Winterwerp, J. C. (2009) SST observations of upwelling induced by tidal straining in the Rhine ROFI. Continental Shelf Research, 29, 263-277.
Burchard, H. (1999) Recalculation of surface slopes as forcing for numerical water column models of tidal flow. Applied Mathematical Modelling, 23, 737-755.

Joordens, J. C. A., Souza, A. J. and Visser, A. (2001) The influence of tidal straining and wind on suspended matter and phytoplankton distribution in the Rhine outflow region Continental Shelf Research, 21, $301-325$

Münchow, A. and Garvine, R. W. (1993) Buoyancy and wind forcing of a coastal current. Journal of Marine Research, 51, 293-322.

Pawlowicz, R., Beardsley, B. and Lentz, S. (2002) Classical tidal harmonic analysis including error estimates in MATLAB using T_TIDE. Computers and Geosciences, 28, 929-937.

de Ruijter, W.P.M., Visser, A.W. and Bos, W.G. (1997) The Rhine outflow: A prototypical pulsed discharge plume in a high energy shallow sea. Journal of Marine Systems, 12, 263 - 276.

Simpson, J. H., Brown, J., Matthews, J. and Allen, G. (1990) Tidal Straining, Density Currents, and Stirring in the Control of Estuarine Stratification, Estuaries, 13, 125-132.

Souza, A. and Simpson, J. H. (1996) The modification of tidal ellipses by stratification in the Rhine ROFI. Continental Shelf Research, 16, 997-1007.

Stacey, M. T., Burau, J. R. and Monismith, S. G. (2001) Creation of residual flows in a partially stratified estuary. Journal of Geophysical Research, 106, 17013-17037.

Umlauf, L., and Burchard, H. (2005) Second-order turbulence closure models for geophysical boundary layers. A review of recent work, Continental Shelf Research, 25, 795-827.

Visser, A.W., Souza, A. S., Hessner, K. and Simpson J. H. (1994) The effect of stratification on tidal current profiles in a region of freshwater influence. Oceanologica Acta, 17, 369-381. 